\title{
Metabolic profiling as a tool for prioritizing antimicrobial compounds
}

\author{
Changsheng $\mathrm{Wu}^{1,2} \cdot$ Young Hae $\mathrm{Choi}^{2} \cdot$ Gilles P. van Wezel ${ }^{1,3}$
}

Received: 3 July 2015 / Accepted: 25 July 2015 / Published online: 3 September 2015

(C) The Author(s) 2015. This article is published with open access at Springerlink.com

\begin{abstract}
Metabolomics is an analytical technique that allows scientists to globally profile low molecular weight metabolites between samples in a medium- or highthroughput environment. Different biological samples are statistically analyzed and correlated to a bioactivity of interest, highlighting differentially produced compounds as potential biomarkers. Here, we review NMR- and MSbased metabolomics as technologies to facilitate the identification of novel antimicrobial natural products from microbial sources. Approaches to elicit the production of poorly expressed (cryptic) molecules are thereby a key to allow statistical analysis of samples to identify bioactive markers, while connection of compounds to their biosynthetic gene cluster is a determining step in elucidating the biosynthetic pathway and allows downstream process optimization and upscaling. The review focuses on approaches built around NMR-based metabolomics, which enables efficient dereplication and guided fractionation of (antimicrobial) compounds.
\end{abstract}

Keywords Metabolomics · NMR · Antibiotic production $\cdot$ Streptomyces $\cdot$ Antimicrobial drug resistance

Special Issue: Natural Product Discovery and Development in the Genomic Era. Dedicated to Professor Satoshi Ōmura for his numerous contributions to the field of natural products.

Gilles P. van Wezel

g.wezel@chem.leidenuniv.nl; g.wezel@biology.leidenuniv.nl

1 Molecular Biotechnology, Institute of Biology, Leiden University, Sylviusweg 72, 2333 BE Leiden, The Netherlands

2 Natural Products Laboratory, Institute of Biology, Leiden University, Sylviusweg 72, 2333 BE Leiden, The Netherlands

3 Department of Microbial Ecology, Netherlands Institute of Ecology (NIOO-KNAW), Wageningen, The Netherlands

\section{Introduction}

The discovery and development of antibiotics to treat bacterial infections is one of the greatest triumphs of modern medicine. However, the exponential increase of antimicrobial resistance means that bacterial infections now once more pose a major threat to human health [126]. The high frequency of re-discovery of known molecules thereby frustrates screening efforts, and this necessitates new approaches to bolster the antibiotic pipelines $[6,23$, 39, 95]. Filamentous fungi and bacteria of the order of Actinomycetales are the major producers of biomedical and agricultural natural products, and these microorganisms are responsible for producing the vast majority of the known antibiotics $[9,85]$. Some two-thirds of all antibiotics are produced by actinomycetes, the majority of which are sourced by members of the genus Streptomyces. However, this is likely to represent only a tiny portion of the repertoire of total chemical space of bioactive compounds that these microorganisms may produce [9, 85]. Firstly, while the number of filamentous microbes in soil and marine environments is enormous, the bulk of them resist cultivation in the laboratory and thus escape screening and exploitation [53]. Recent work showed that enabling growth of these 'uncultivable' microorganisms might open up a new area of the chemical space of natural products $[68,129]$. Secondly, many natural product biosynthetic gene clusters (BGCs) of cultivable microbes remain silent during standard laboratory cultivation $[10$, 136]. As an example, genome sequencing of actinomycetes revealed that the producing capacity of even the best-studied model organisms has been grossly underestimated $[8,27,51,119]$. Thirdly, those gene clusters that are expressed, particularly if expression is relatively low as compared to other bioactive compounds produced by 
the same organism, often escape discovery due to the very demanding chemical analysis or chromatographic purification that is required [94]. New approaches are therefore required to exploit the huge unexplored reservoir of bioactive natural products and rejuvenate the drug-discovery pipelines.

The preferred method of identifying compounds in complex mixtures is metabolomics, which is a high-throughput analytical technique that offers a global analysis of the products of all cellular metabolic reactions, regardless of the reactions that lead to their production [96]. Spectroscopic techniques, and in particular nuclear magnetic resonance (NMR) and mass spectrometry (MS), are applied to chemically profile the metabolites that are produced by microorganisms. In connection with a wide range of chemometric methods, the metabolic differences among experimental groups are subsequently unraveled by comparison $[38,131]$. In this review, we discuss ways to enforce fluctuations in the production of bioactive compounds, and the application of metabolomics to facilitate uncovering those compounds, whereby we zoom in on NMR-based metabolic profiling methods, which are less commonly applied in microbial drug discovery.

\section{Approaches to elicit antibiotic production}

Genome mining of actinomycetes on average reveals the presence of 30-40 secondary metabolite BGCs per species [125]. Only a small number of these gene clusters has been matched to a natural product. A major problem is that many BGCs remain silent or poorly expressed under routine screening conditions. If we are to even start attempting to visualize these compounds by metabolomics approaches, their activation is the first essential step. Generic approaches to activate silent antibiotics to uncover the hidden chemical diversity include: (i) changing the growth media [14, 137]; (ii) inducing antibiotic resistance, e.g. to streptomycin [91] or rifampicin $[37,48,90]$; (iii) the addition of chemical elicitors, such as $\mathrm{N}$-acetylglucosamine [98], $\gamma$-butyrolactones [50, 128], or histone deacetylase inhibitors [2]; and (iv) microbial cocultivation [11, 49, 109]. Instead of inducing the production of an antibiotic, an interesting alternative may be offered by screening for inducible resistance, in particular associated with classes of antibiotics that are less frequently identified in classical screens. Growth on media containing the glycopeptide vancomycin was used to select actinomycetes that produce (and are therefore resistant to) glycopeptide antibiotics. Subsequent phylogeny-based screening based on specific biosynthetic genes led to the identification of the novel glycopeptide antibiotic pekiskomycin [114].
In terms of the activation of antibiotic production, a concept study was recently done using a collection of some 800 strains that were grown under 40 different growth conditions and then assayed for changes in the production of antimicrobial activity against the so-called ESKAPE pathogens [137]. This showed that many strains that fail to produce antibiotics under routine growth conditions, produce bioactivities that inhibit the growth of MDR pathogens under specific nutritional conditions or after addition of elicitors [137].

\section{Harnessing the regulatory mechanisms that control antibiotic biosynthesis}

To develop new directed approaches, it is imperative that we better understand the underlying regulatory networks. The regulation of antibiotic production involves multiple regulatory cascades and networks. Here, we will guide the reader with some general principles gleaned from the model organism Streptomyces coelicolor; for more extensive reviews on the control of antibiotic production we refer the reader elsewhere $[13,69,100,120]$.

Antibiotic BGCs specify biosynthesis and modification, resistance, transport and pathway-specific control. The best-studied example of cluster-encoded, pathwayspecific activators is that of the Streptomyces antibiotic regulatory proteins (SARPs). SARPs typically bind to direct repeats in promoter regions of biosynthetic genes, thereby activating transcription of some or all of the antibiotic biosynthetic genes in the cluster [127]. In S. coelicolor, the pathway-specific regulatory genes actII-ORF4, $c d a R$ and redD encode the SARPs for actinorhodin (ACT), calcium-dependent antibiotic (CDA) and undecylprodigiosin (RED) production, respectively. Of these, actII-ORF4 and redD have been extensively studied. Deletion of these genes abolishes the production of actinorhodin or undecylprodigiosin, respectively [36], and their transcription is activated in a growth phase-dependent manner $[4,113]$. Interestingly, positioning redD behind a developmental or nitrogen-responsive promoter is sufficient to produce undecylprodigiosin in aerial hyphae or bring it under nitrogen control, respectively, which suggests a lack of downstream control [122]. Hence, one effective approach to activate gene clusters is overexpression of their activator genes, but this involves genetic manipulation which is not amenable to high-throughput approaches.

Recent years have underlined the importance of global regulators as a higher order regulatory network, and their possible application for the activation of antibiotic production. Many pleiotropic regulators characterized so far are required only under specific environmental conditions [12, 121]. The nutrient sensory GntR-family regulator DasR 
controls among others aminosugar metabolism and transport, the chitinolytic system and antibiotic production $[21,22,26$, 97, 98, 112]. DasR is a highly pleiotropic regulator, as demonstrated by recent systems biology analysis of chitin- or $N$-acetylglucosamine-induced cultures of $S$. coelicolor $[84$, 110]. DasR directly controls the transcription of actII-ORF4 and $r e d D$ as well as $r e d Z$, a response regulator required for the activation of $r e d D$ and thus of undecylprodigiosin production [98]. Systems-wide DNA binding experiments using ChIP-chip analysis revealed that in S. coelicolor DasR likely controls all pathway-specific activator genes [110], but this appears to be more an exception than a rule. The activity of DasR is modulated by metabolic derivatives of $\mathrm{N}$-acetylglucosamine, and addition of this amino sugar to the culture media activates antibiotic production in several actinomycetes, including cryptic antibiotics [98].

Interesting cross-talk is seen for DasR with other higher order antibiotic regulators. One is the TetR-family regulatory protein AtrA that in $S$. coelicolor is required for the transcription of actII-ORF4 [118] and in S. griseus of strR, the pathway-specific activator gene of streptomycin production [47]. The antibiotic activating role of AtrA may be widespread, as suggested by recent data that AtrA also controls biosynthesis of the important lipoglycopeptide antibiotic daptomycin in Streptomyces roseosporus [76]. AtrA is controlled by the level of phosphate and repressed by the PhoRP system [101]. AtrA activates development [60] as well as $N$-acetylglucosamine import [88], and thus antagonizes the repressing activities of DasR, whereby the metabolic balance likely plays a deciding role on the net outcome. Further complexity is offered by Rok7B7, a member of the ROK family of proteins, which are predominantly sugar regulatory proteins and sugar kinases, including glucose kinase $[73,115]$. Rok7B7 also pleiotropically affects primary and secondary metabolism, and is like AtrA required for actinorhodin production [79, 111]. Recent evidence suggests that Rok7B7 may be activated by a derivative of the C5 sugar xylose [111].

Other pleiotropic antibiotic regulators involved in the control of actII-ORF4 are the large SARP-family regulator AfsR and the phosphate regulator PhoP. AfsR derives its name from a putative relationship to synthesis of the hormone-like signaling molecule A-factor, belonging to the $\gamma$-butyrolactones. The A-factor-responsive AdpA controls the onset of development and antibiotic production in S. griseus [46, 116], but the precise relationship with AfsR (if any) so far remains unresolved. In S. coelicolor, AfsR is conditionally required for Act and Red production [36] and its control is somehow transmitted through control of the small downstream gene afs $S$, thereby activating its transcription [67]. While the precise function of afsS is unclear, similarly to AtrA, its pleiotropic and positive effect on antibiotic production makes it an attractive target for the activation of antibiotic production. PhoP represses actinorhodin production in response to phosphate [106], and it may also relay its control via afs $S$ [101] These are examples to highlight the complexity of the control of antibiotic production, whereby an astonishing number of around 15 regulatory proteins have been shown to control actII-ORF4 alone [121]. Improved understanding of these multiple and intertwined regulatory networks will allow scientists to design new approaches to activate poorly expressed BGCs.

\section{Connecting eliciting approaches to metabolomics-driven lead discovery}

In the framework of this review, the activation of gene expression is important to activate silent gene clusters and particularly to achieve significant fluctuation of the production of (cryptic) antibiotics and thus differential bioactivity between cultures; this serves as enabling technology for statistical correlation between a bioactivity of interest and the responsible (sought-after) compounds. Having established such differential expression, the next challenge is to efficiently identify the induced antimicrobial compounds against a background of an inevitably highly complex metabolome matrix.

Metabolomics is an effective tool for facilitating the discovery of new antibiotics, because it allows the multivariate comparison of active and inactive metabolic samples, highlighting particularly the differentially produced compounds, which serve as potential biomarkers, thereby avoiding chemical redundancy in the very early stage [59, 63 , 93]. Integrating metabolomics approaches with new eliciting strategies should allow scientists to streamline their drug-discovery pipeline, so as to prioritize novel molecules over repeated (and frustrating) isolation of known molecules. A schematic representation of a feasible antibiotics discovery pipeline based on NMR-based metabolomics is presented in Fig. 1. Compounds can be readily identified in complex biological matrices without time-consuming chromatographic separation, further aided by $2 \mathrm{D}$ NMR experiments. In the next section, we detail some of the NMR techniques that are most appropriate for metabolomics approaches.

\section{Metabolomics of natural products based on NMR spectroscopy}

NMR techniques that are most frequently used in NMR metabolomics are ${ }^{1} J$-resolved, COSY, TOCSY, HSQC, and HMBC [58, 59, 74, 89]. ${ }^{1} \mathrm{H}$ NMR signals corresponding to molecules that exist in both the active and the inactive groups are discarded based on lack of statistical relevance [105]. Chemometric analysis is then used for further data 

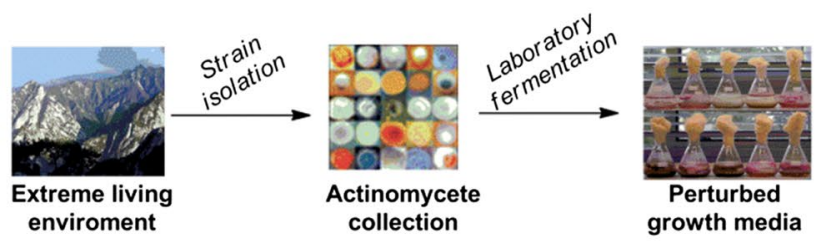

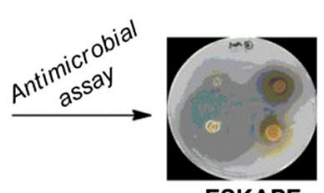

ESKAPE pathogens

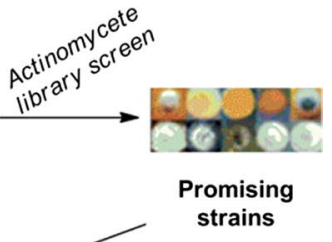

trains
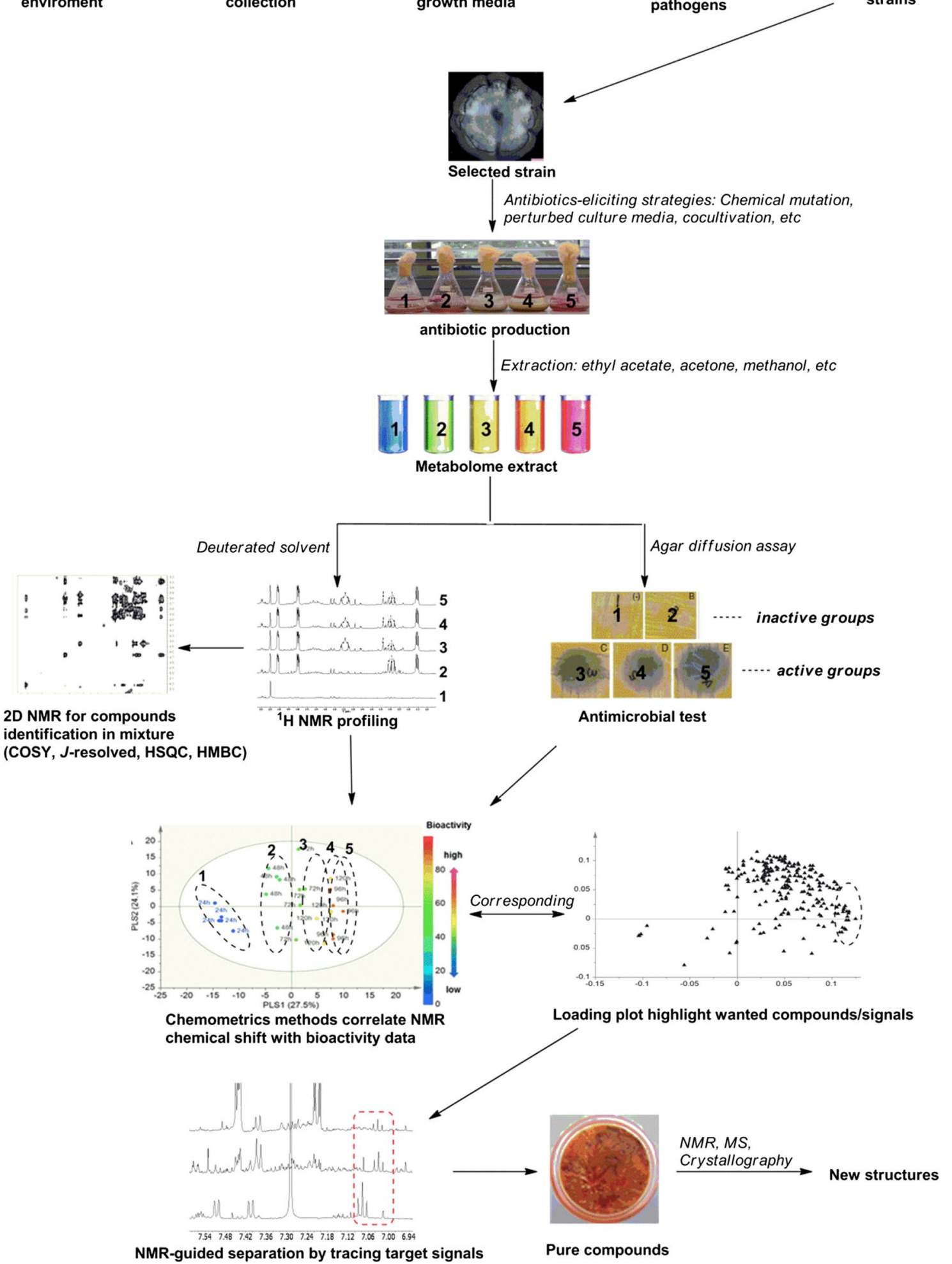
4 Fig. 1 A pipeline for the discovery of antibiotics produced by actinomycetes based on NMR-based metabolomics. Strains are subjected to eliciting approaches to activate the production of poorly expressed antimicrobials, followed by NMR-based metabolomics to identify the bioactive molecules. ${ }^{1} \mathrm{H}$ NMR profiling of active and inactive groups, aided by 2D NMR, allows dereplication of known molecules and chemometric methods then correlate proton signals in the active fractions to the bioactive compound(s)

mining of the ${ }^{1} \mathrm{H}$ NMR data, extracting information that is intractable to visual detection. In principle, the methodology of NMR measurements, spectral data preprocessing, and multivariate data analysis basically follow a protocol that was originally designed for analysis of plant metabolites [58]. The ${ }^{1} \mathrm{H}$ NMR signals correlated with the better bioactivity and separation of the active from the inactive groups are used as probing tools for NMR-guided isolation of the sought-after bioactivity. Advantages of NMRbased over MS-based (LC-MS or GC-MS) metabolomics are: (i) the chemical shifts and splitting patterns of proton resonance data provide partial structural information that allows early assessment of the type of compound causing the bioactivity, thus aiding in avoiding redundancy; (ii) the analysis of crude mixtures can be done in very short time (in the order of minutes), with high signal robustness (i.e. minimum technical variation), so as to guide scientists in a medium- to high-throughput environment. These advantages should be weighed against the lack of true high-throughput application, which is a key selling point of MS-based approaches. As soon as the major interfering signals are removed from the NMR spectra, the material (even if not yet pure) is likely of sufficient quality for full structure elucidation. In some cases, structural elucidation of unknown compounds is challenging, especially for those entities with unprecedented molecular scaffold. Twodimensional NMR (2D NMR) techniques have formed the foundation of most contemporary approaches for structure elucidation [16], allowing assembly of the molecular architecture by defining atom-to-atom connectivity. In general, NMR-based metabolomics uses a combination of 2D NMR techniques for deconvoluting metabolites in congested mixtures, namely $J$-resolved, ${ }^{1} \mathrm{H}$-based $2 \mathrm{D}$ (COSY and TOCSY), ${ }^{13} \mathrm{C}$-based 2D NMR (HSQC and HMBC) [16]. $J$-resolved solves the signal purity of ${ }^{1} \mathrm{H}$ NMR by showing splitting pattern with coupling constants in F2 axis which requires for chemical structures of corresponding signals. COSY and TOCSY give information of ${ }^{1} \mathrm{H}$ connectivity within the same molecule. Along with the connectivity, the ${ }^{1} \mathrm{H}$-based COSY and TOCSY also help signal identification in overlapped regions. Many signals are overlapped which obscures some of the peaks in the mixture, but these can be deconvoluted by the correlations in the 2D NMR spectra. ${ }^{13} \mathrm{C}$-related spectra such as HSQC and HMBC give more detailed structural information, particularly for the carbon
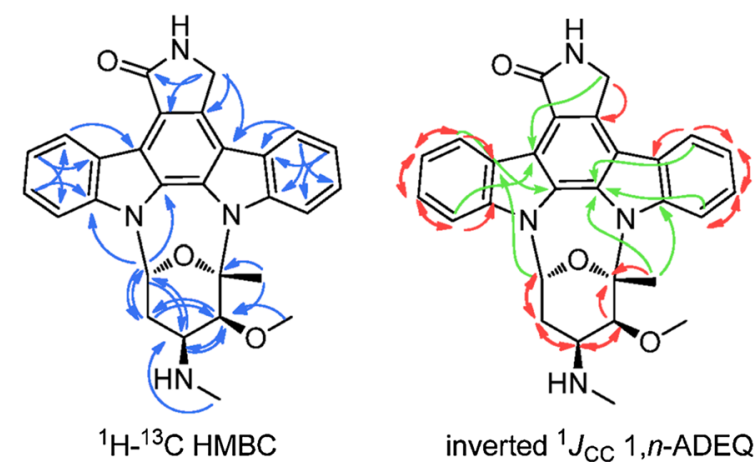

inverted ${ }^{1} J_{\mathrm{CC}} 1, n$-ADEQUATE

Fig. 2 Diagram of HMBC (blue anticlockwise semi-circle arrows), and inverted ${ }^{1} J_{\mathrm{CC}} 1, n$-ADEQUATE correlations by using the proton-deficient alkaloid staurosporine as an example. The skeleton of this model compound can be unequivocally assigned by HMBC + inverted ${ }^{1} J_{\mathrm{CC}} 1, n$-ADEQUATE strategy. In inverted ${ }^{1} J_{\mathrm{CC}}$ $1, n$-ADEQUATE, ${ }^{1} J_{\mathrm{CC}}$ correlations are shown as red clockwise semicircle arrows, while important ${ }^{3} J_{\mathrm{CC}}$ correlations are shown as green clockwise semi-circle arrows

skeleton. Although important for identifying the carbon skeleton of organic compounds, ${ }^{13} \mathrm{C}$-NMR is rarely applied in NMR-based metabolomics because of the low abundance of ${ }^{13} \mathrm{C}$ in nature and its long relaxation time, and also because ${ }^{13} \mathrm{C}$ broad-band decoupling cannot be used quantitatively. HSQC and HMBC are therefore primarily applied to support the ${ }^{1} \mathrm{H}$ NMR data.

Deciphering the structure of organic molecules by using conventional routine suites, based on for example $J$-resolved-COSY (or TOCSY), HSQC and HMBC [87] often gives rise to misassignment. This partly arises from the inherent challenges of differentiating two-bond heteronuclear $\left(\mathrm{H} \rightarrow \mathrm{C},{ }^{2} J_{\mathrm{CH}}\right)$ correlations from three-bond correlations $\left({ }^{3} J_{\mathrm{CH}}\right)$ in the $\mathrm{HMBC}$ spectrum. In addition, as HMBC normally just provides ${ }^{2} J_{\mathrm{CH}}$ and ${ }^{3} J_{\mathrm{CH}}$ but rarely ${ }^{4} J_{\mathrm{CH}}$ correlations, structure elucidation becomes progressively challenging the more molecules become proton-deficient [104]. To address these problems, many other approaches have been tried such as combined HSQC-TOCSY [61]. Researchers from Merck proposed that adequate sensitivity double-quantum ( $1, n$-ADEQUATE) NMR spectroscopy should be reconsidered as a complement for HMBC in structure elucidation [77]. 1,1-ADEQUATE exclusively presents ${ }^{1} J_{\mathrm{CC}}$ correlations and can help distinguish ${ }^{2} J_{\mathrm{CH}}$ from ${ }^{3} J_{\mathrm{CH}}$ correlations in the HMBC spectrum, which would be a powerful method for determining the protonrich small molecules by using a combination of 1,1-ADEQUATE + HMBC $[19,83] .1, n$-ADEQUATE experiments predominantly yield homonuclear ${ }^{3} J_{\mathrm{CC}}$ correlations (equal to ${ }^{4} J_{\mathrm{CH}}$ ) that are difficult to obtain with HMBC NMR. This feature makes 1, $n$-ADEQUATE a complement for HMBC in defining proton-deficient structures, such as a large group of aromatic polyketides (PKS) produced by actinomycetes 
$[17,83]$. Furthermore, newly developed inverted ${ }^{1} J_{\mathrm{CC}} 1$, $n$-ADEQUATE spectroscopy allows the integration of 1,1-ADEQUATE and $1, n$-ADEQUATE information in a single spectrum, while they remain distinguished by plotting the output in different colors (Fig. 2) [78].

Though NMR spectroscopy is undoubtedly powerful in the structure elucidation, it works better on pure organic compounds, as otherwise signal-overlapping issues come into play. To address this, chromatography-hyphenated NMR (HPLC-NMR) has been introduced into metabolic analysis [130]. The major advantages of on-flow HPLCNMR lie in the real-time access to structure information of chromatographic peaks by using NMR spectrometers as detector [75]. To balance the inherent lower sensitivity of NMR spectra and the limited injection volume onto the HPLC unit, solid-phase-extraction (SPE) is coupled to trap the analytes onto an identical SPE cartridge when repeated HPLC analysis, followed by final elution with a deuterated solvent into miniaturization tube for NMR analysis [103]. By using this LC-SPE-NMR approach [64, 108], comprehensive structural information about chemical composition of crude extracts can be obtained online, thus enabling early and prospective assessment of the valuable components of an extract or fraction [52]. Furthermore, when integrating MS into the system, like LC-DAD-SPE-MSNMR instrumentation [33, 70], the architecture of novel compounds can be elucidated de novo and online without laborious purification of the analyte(s) from its highly complex matrix.

\section{Connecting genotype to chemotype: integrating genomics with metabolomics}

Before looking at applications of metabolomics to identify novel compounds, in this section we will look into how metabolomics may aid in connecting a natural product of interest to its BGC. This is a crucial step as it facilitates molecular approaches such as directed mutagenesis, overexpression of pathway-specific regulators and heterologous expression. Furthermore, identification of the gene cluster is often required for determining the precise biosynthetic pathway.

Next-generation sequencing (NGS) technologies have uncovered the genetic architecture of thousands of BGCs, and this has revolutionized the drug-discovery approaches [24]. Exploiting this rapidly increasing source of information, a recent network analysis of the phylogeny and distribution of BGCs in microbial genomes revealed a vast number of yet underexplored genetic resources, belonging to many hundreds of gene cluster families [20].

Gene clusters such as those for PKS or nonribosomal peptides (NRPS) are readily identified using bioinformatics, and to some extent the domain structures of the biosynthetic proteins allows prediction of the molecule that they specify $[5,66]$. In recent years, excellent bioinformatics packages have been developed for the identification of BGCs. These include antiSMASH (ANTIbiotics \& Secondary Metabolite Analysis SHell [81] and SMURF (Secondary Metabolite Unknown Regions Finder), as well as packages that enable the identification of biosynthesis genes for specific subclasses of NPs (reviewed in [34] ). Examples are SBSPKS (Structure Based Sequence Analysis of Polyketide Synthases) for polyketide BGCs [3], NRPSPredictor for NRPS gene clusters [99] and BAGEL for the identification of biosynthetic clusters for bacteriocins and lantibiotics [28].

\section{From genotype to chemotype: bioinformatics-guided natural product discovery}

How can we determine whether the compound that is derived from a given BGC is novel (genotype to chemotype) or, conversely, link a natural product of interest to its gene cluster (chemotype to genotype)? The genotype-tochemotype roadmap (Fig. 3a) $[56,57]$ provides a glimpse of 'hidden treasures', e.g. aided by the exploitation of pathway-specific regulators [40,65] or via heterologous gene expression [7, 92]. Metagenomic libraries from environmental samples thereby allow scientists access to the 'dark matter', namely the vast biosynthetic potential of uncultivable microbes [15, 54]. However, an intrinsic disadvantage of genome-based bioprospecting is that current technologies target a single BGC at the time, which is timeconsuming, while the discovery efficiency is low as it is very difficult to prioritize 'promising' gene clusters. After all, if a gene cluster appears novel, it does not mean that the compound has not already been identified in HT screening regimes in the pre-genomic era. We predict, however, that synthetic biology and heterologous expression of gene clusters will soon become part of a more automated environment, which would make these approaches much more feasible. In addition, approaches directed at the (heterologous) expression of gene clusters depend on the functional analysis of biosynthetic enzymes and/or detection of intact clusters, while biosynthetic reactions may be catalyzed by enzymes that are not encoded by the gene cluster itself and/ or by enzymes with low specificity [102], or are catalyzed non-enzymatically [80, 132]. Indeed, metabolites are the end products of many cellular processes, so that the bioactive end product is not necessarily specified by individual genes or clusters [96].

In the case of intertwined metabolic and biosynthetic pathways giving rise to a single compound, targeted genomic approaches lose their effectiveness [117, 124, 132]. In such cases, metabolomic approaches are required 


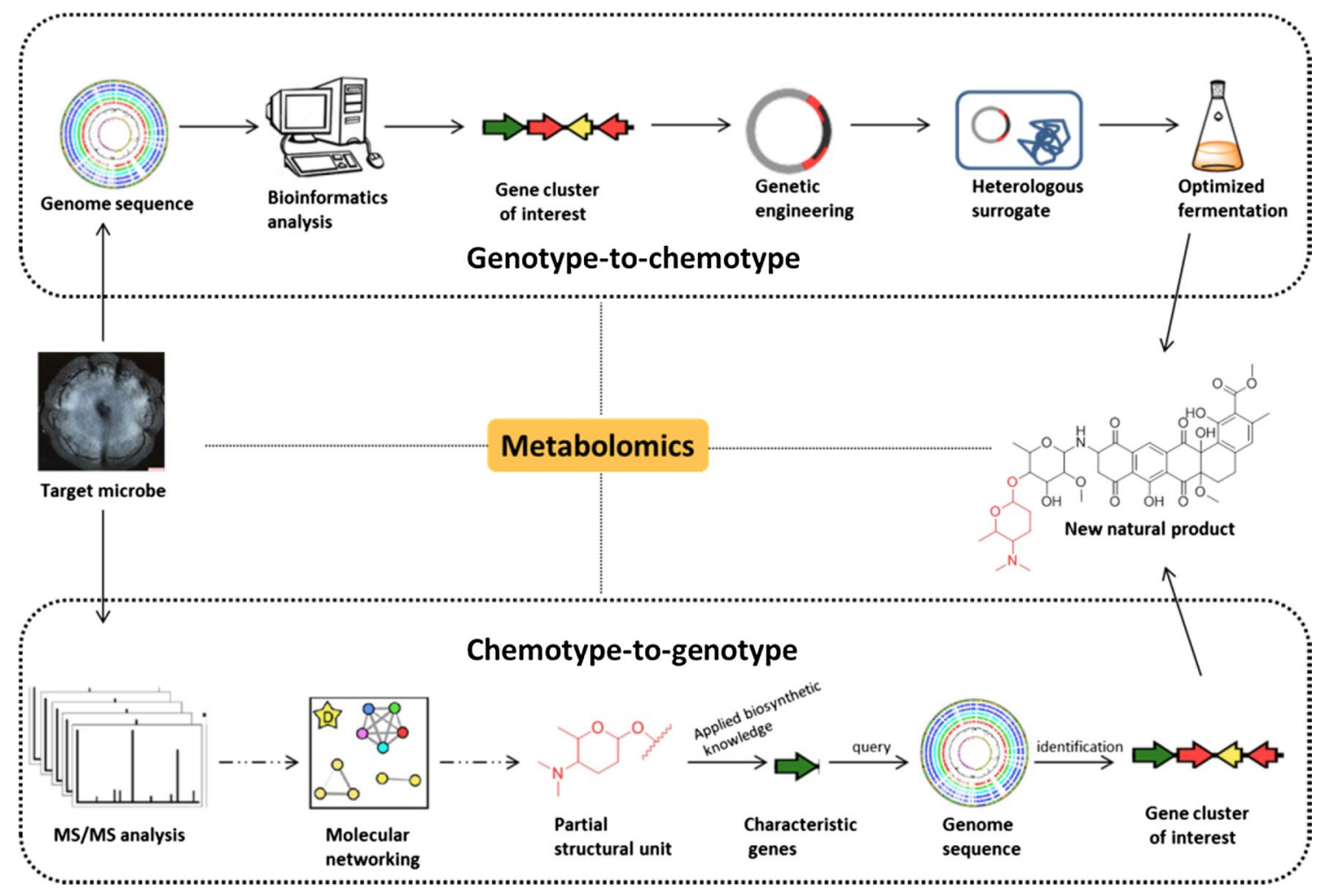

Fig. 3 General workflows for genotype-to-chemotype (a) and chemotype-to-genotype (b) genome mining for natural product discovery

to bridge the gap between bioinformatics-driven gene cluster analysis and NP discovery [30, 62]. The fundamental principle is based on the fact that structurally related NPs are typically characterized by similar MS/MS fragmentation patterns. The MS/MS structural relatedness among molecules can be detected in an automated manner, and can subsequently generate a molecular network wherein analogues cluster together. In this way, known structures and "known unknowns" can be identified in extracts, offering an effective dereplication strategy and a way of prioritizing novel compounds [134].

\section{From chemotype to genotype: metabolomics to identify biosynthetic gene clusters}

MS/MS analysis allows the detection of "structural unit tags" or building blocks whose biosynthesis needs specific enzymes bearing substrate specificity. Candidate genes can be used as query against the genome databases to locate the target gene cluster for the compound(s) of interest. MS-based metabolomics in conjunction with molecular networking builds up a chemotype-to-genotype roadmap (Fig. 3b) [44, 56, 57, 62] for NP discovery, directly linking secondary metabolites to their corresponding gene clusters. Examples for this concept include peptidogenomics [56, 86], glycogenomics [57] and natural product proteomining
[43]. Peptidogenomics is an MS-based genome-mining method that links peptide natural products to their BGCs through iteratively matching tandem MS $\left(\mathrm{MS}^{\mathrm{n}}\right)$ sequence tagging with genomics-derived peptide structures [56], supported by software automation packages such as the recently developed Pep2Path [82]. For an excellent review of peptidogenomics techniques and their application we refer the reader elsewhere [62]. Glycogenomics is a chemotype-to-genotype approach for fast characterization of glycosylated natural products (GNPs) and their biosynthetic pathways. Tandem mass spectrometry $\left(\mathrm{MS}^{\mathrm{n}}\right)$ allows rapid identification of the structural information of sugar substituents of GNPs in microbial metabolic extracts [32, 45]. The biosynthesis of certain sugars need specific enzymes; as an example, genes for forosamine production encode 2,3- and 3,4-dehydratases, 3-ketoreductase, aminotransferase and $\mathrm{N}, \mathrm{N}$-dimethyltransferase. Applying the bacterial sugar biosynthetic knowledge, $\mathrm{MS}^{\mathrm{n}}$-characterized glycosyl groups can be matched to corresponding glycosylation genes. In microbial genomes, the glycosylation-associated biosynthetic genes are usually co-clustered with those for a wide range of aglycones. Programs such as antiSMASH are specifically designed with the identification of such signature BGCs in mind. The relevant aglycone biosynthetic genes are then identified, which in turn guides further isolation and structural identification of glycoconjugates by applying 
Fig. 4 Chemical structures of the compounds mentioned in the final section of the review ("Experimental approaches based on NMR metabolomics")<smiles>NC(=O)CC(O)CC1CC(=O)c2c(O)cccc2C1=O</smiles><smiles>COc1cc2c(cc1O)OC(=O)C1NCCS(=O)(=O)C21</smiles>

iotrochotazine $A$<smiles>CC(C)=CCc1cccc2c1NC(=O)C2=O</smiles>

7-prenylisatin<smiles>O=C1NC(Cc2ccccc2)C(=O)NC1Cc1ccccc1</smiles>

cyclo(Phe-Phe)<smiles>CC[C@H](C)C(=O)O[C@H]1[C@@H](O)[C@H](C)C[C@H](OC(C)(C)C2CC=C(C)CC2)[C@H]1OC(C)=O</smiles><smiles>CC[C@H](C)C(=O)O[C@H]1[C@@H](C)C[C@@H](OC(C)(C)[C@H]2CC=C(C)CC2)[C@H](OC(C)=O)[C@@H]1O</smiles>

venuloside $\mathrm{D}$ knowledge of the aglycone-specific BGC. As aglycones could be any type of structural scaffolds, for sugar-modified NPs, glycogenomics has an advantage over peptidogenomics. This technique therefore expands the applicability of MS-guided genome mining for different classes of NPs, such as nonribosomal and ribosomal peptides, PKS, terpenes, and alkaloids [32]. Furthermore, since glycosylated products are produced via the decoration of an aglycone, which is often bioactive by itself, we envisage that glycogenomics can be extended to discover even non-glycosylated NPs that serve as intermediates for final GNPs.

Natural product proteomining is based on the concept that gene cluster expression profiles correlate directly to the level of the corresponding natural product [43]. When growth conditions are chosen such that a bioactivity of interest is differentially produced, e.g. high under some conditions and intermediate or not at all in others, statistical correlation between bioactivity (metabolomics) and gene expression profiles (proteomics, RNAseq) will allow prioritizing those gene clusters with the optimal match. Since the metabolomics will also provide clues on the type of molecule, evidence of the BGC responsible for the product of interest can thus be obtained, with the predictive value depending on the number of candidate BGCs present in the genome and the number of samples analyzed [43]. The concept of metabolomics aiding genomics in finding new NPs is also exemplified by the case of myxoprincomide from the Myxococcus xanthus [25]. Initially, 13 BGCs in M. xanthus DK1622 were found for which the metabolites remained elusive. After targeted inactivation of these cryptic gene clusters, MS-based metabolomics was applied to pairwise compare extracts of mutants and the wild-type strain, highlighting the subtle metabolic differences by statistical filtering. Thus, a metabolite with molecular formula
$\mathrm{C}_{45} \mathrm{H}_{76} \mathrm{~N}_{10} \mathrm{O}_{16}$ was assigned to a NRPS/PKS hybrid gene cluster and identified as a molecule with the unprecedented structural skeleton of myxoprincomide. Gene knockout/ untargeted metabolomics strategy could also facilitate discovery of intermediates and/or new side products of biosynthesis pathway, as exemplified by characterization of 2-alkyl-4,5-dihydrothiazole-4-carboxylates from Pseudomonas aeruginosa [55, 123]. Comparison of the extracellular metabolome of $P$. aeruginosa pch mutants with that of the wild-type strain identified 198 secondary metabolites regulated by these pathway-specific pch genes. Therefore, perturbation of the expression of global or pathway-specific regulators followed by metabolomics is a promising strategy to rapidly connect molecules to genes or gene clusters.

\section{Experimental approaches based on NMR metabolomics}

As explained above, metabolomics approaches allow elucidating the nature of poorly bioactive molecules in complex mixtures, and for this achieving differential production of the bioactivity of interest is a key step. Such fluctuation may be achieved by among others different culturing conditions, inducing drug-resistance or by co-culturing [38, 131]. NMR-based metabolomics is very common for identifying plant NPs, but has yet seen relatively little application in microbial drug discovery. A general scheme is presented in Fig. 1. We recently applied NMR-based metabolomics for the mining of novel soil isolates with promising antibiotic-producing potential, of which we provide a few examples here for illustration purposes. To identify a bioactivity produced by the soil isolate Streptomyces sp. MBT70, the strain was grown in media supplemented 


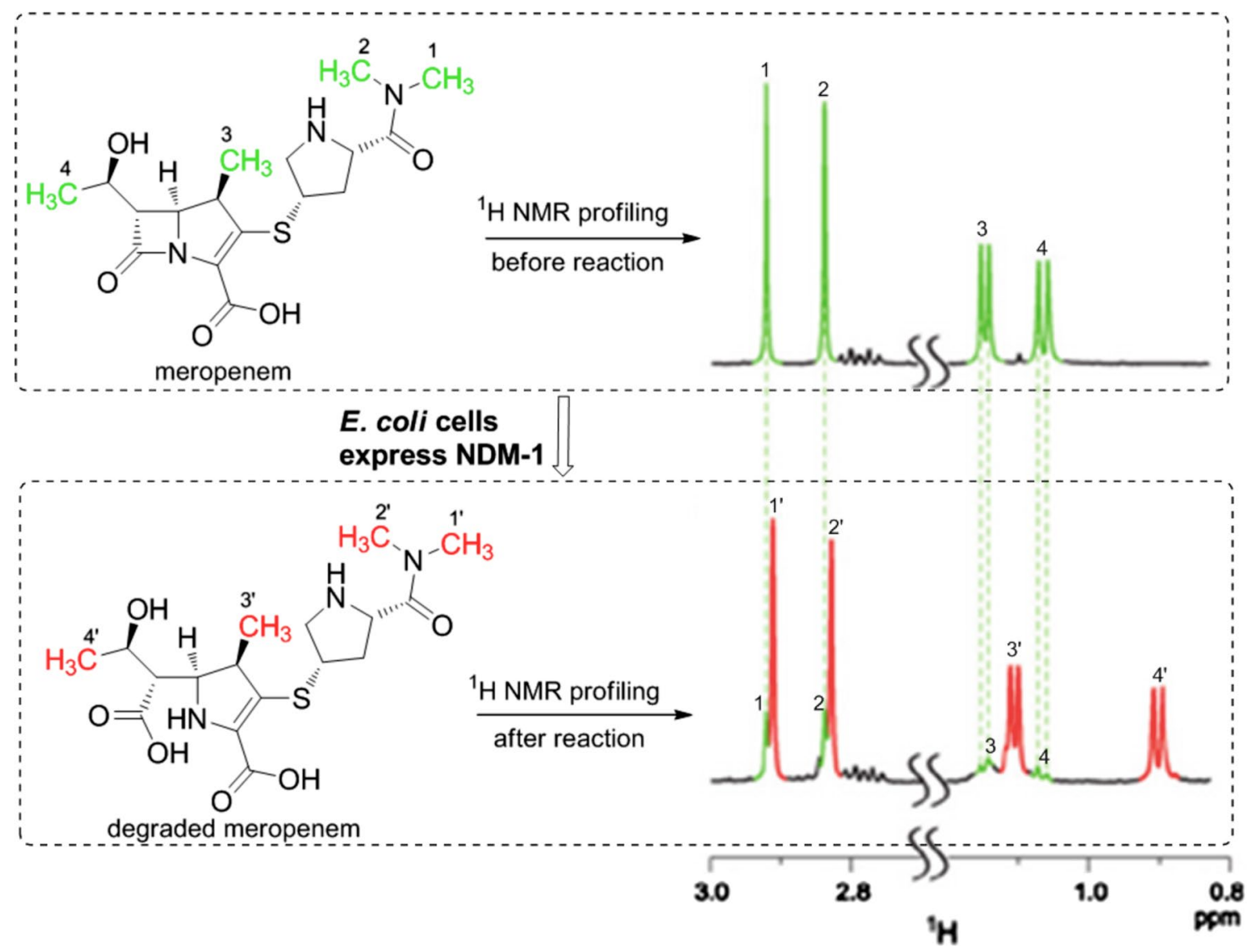

Fig. 5 In vivo ${ }^{1} \mathrm{H}$ NMR spectroscopy monitors NDM-1 activity in living Escherichia coli cells. Cyclic amide ring in $\beta$-lactam antibiotic meropenem is hydrolyzed under catalysis of enzyme NDM-1. The ${ }^{1} \mathrm{H}$ NMR chemical shifts of four characteristic methyls (green) in the

with different additives followed by ${ }^{1} \mathrm{H}$ NMR spectroscopy and statistical comparison of the extracts by partial least square modeling-discriminant analysis (PLS-DA). A main discriminator between bioactive and inactive cultures was a signature $\mathrm{H}-5$ residue belonging to a naphthoquinone. Further HPLC fractionation targeting naphthoquinones then led to the isolation and identification of juglomycin C amide (Fig. 4) [43]. The generation of streptomycin resistant $\left(\mathrm{Str}^{\mathrm{R}}\right)$ mutants in soil isolate Streptomyces sp. MBT28 resulted in the specific activation of a bioactive compound, which was subsequently identified by comparing the active $\left(\mathrm{Str}^{\mathrm{R}}\right.$-induced) and non-active fractions by ${ }^{1} \mathrm{H}$ NMR and statistical analysis by projection to latent structures (PLS); this allowed correlation of the enhanced bioactivity to a set of distinctive aromatic signals. NMR-guided separation by tracking characteristic ${ }^{1} \mathrm{H}$ NMR signals as probes, resulted in the characterization of the isatin-type antibiotic 7-prenylisatin (our unpublished data). As a third example, co-cultivation of the filamentous model microbes $S$. coelicolor and Aspergillus niger substantially influenced their NPs profiles. NMR spectroscopy of extracts obtained substrate accordingly move upfield in the hydrolytic product (red). This reaction can be monitored in real-time without disturbing the experimental system

from the separate strains and the coculture combined with multivariate data analysis revealed diketopiperazine-type compounds like cyclo(Phe-Phe) (Fig. 4), which were exclusively produced by $A$. niger when grown in co-culture with S. coelicolor [133].

${ }^{1} \mathrm{H}$ NMR based profiling also finds its application in lead discovery. Quinn and coworkers integrated solid phase extraction (SPE) with NMR fingerprinting. An extract library was prepared featuring lead-like enhanced (LLE) fractions selected on the basis of favorable physicochemical properties [18], and this LLE library was subsequently profiled by ${ }^{1} \mathrm{H}$ NMR spectroscopy to present the structural information of the small molecules contained in the library. In this way, the complicated and overlapping ${ }^{1} \mathrm{H}$ NMR spectra typical of crude extracts were avoided by prefractionation, facilitating the detection of minor compounds. Using the proton signals as tracking signals for NMR-guided isolation, an unprecedented scaffold of iotrochotazine A was identified in LLE-fractionated extracts from sponges [41] and low-abundant venulosides C and D (Fig. 4) in extracts from plants [42]. 
An important class of NPs in the fight against antibiotic resistance is that of resistance inhibitors. Penicillins are still the most administered antibiotics [29, 107], but resistance caused by $\beta$-lactamases was discovered almost as soon as the antibiotic itself [1] and has become a major problem for their clinical application [126]. The combined use of $\beta$-lactam antibiotics together with $\beta$-lactamase inhibitors is exemplified by the combination of amoxicillin and clavulanic acid, marketed as Augmentin ${ }^{\circledR}[31,35]$. A targetbased in-cell NMR approach was recently proposed for use in high-throughput screening approaches to identify resistance inhibitors with activity against a specific $\beta$-lactamase [71]. The New Delhi metallo- $\beta$-lactamase (NDM-1), which opens the cyclic amide ring in $\beta$-lactams antibiotics [135], was monitored in real time in E. coli cells by ${ }^{1} \mathrm{H}$ NMR spectroscopy [72]. The approach is summarized in Fig. 5. The chemical shifts of four characteristic methyl groups are different between the substrate meropenem and its NDM1-degraded product, which was used as a reporter of the lytic reaction. Inhibition of NMD-1 enzymatic activity was readily detected since the characteristic methyl groups of meropenem remain unshifted in the ${ }^{1} \mathrm{H}$ NMR spectrum. NMR-guided fractionation was then applied to trace the responsible antibiotic adjuvants in the active fractions.

\section{Conclusions}

In a time where dereplication is one of the major challenges in screening efforts, metabolomics offers an effective strategy to prioritize novel molecules produced by microorganisms. Combination of eliciting strategies with comprehensive chemometric comparison of secondary metabolomes and genomics is an excellent alternative over traditional HT approaches. Metabolomics thereby complements (meta-) genomics and synthetic biology approaches in the mining of producing organisms, in particular for poorly expressed (cryptic) molecules. In addition, connecting chemotype to genotype and vice versa is important to facilitate molecular approaches and to accelerate unraveling of the biosynthetic pathway, and thus enable metabolic engineering and upscaling. Also taking the huge promise of the unculturable microorganisms into account, it is clear that natural product discovery is far from an echo from the past. Instead, as noted by many scientists worldwide, we may well be witnessing a new era of drug discovery, where many different disciplines such as genomics, metabolomics, bioinformatics, synthetic biology, ecology, chemical biology and industrial screening come together to meet the drug-discovery challenges and deliver new solutions to treat infectious diseases associated with drug resistance.
Acknowledgments The work was supported by a CSC PhD fellowship from the Chinese government to $\mathrm{CW}$.

Open Access This article is distributed under the terms of the Creative Commons Attribution 4.0 International License (http://creativecommons.org/licenses/by/4.0/), which permits unrestricted use, distribution, and reproduction in any medium, provided you give appropriate credit to the original author(s) and the source, provide a link to the Creative Commons license, and indicate if changes were made.

\section{References}

1. Abraham EP, Chain E (1940) An enzyme from bacteria able to destroy penicillin. Nature 46:837

2. Albright JC, Henke MT, Soukup AA, McClure RA, Thomson RJ, Keller NP, Kelleher NL (2015) Large-scale metabolomics reveals a complex response of Aspergillus nidulans to epigenetic perturbation. ACS Chem Biol 10:1535-1541

3. Anand S, Prasad MV, Yadav G, Kumar N, Shehara J, Ansari MZ, Mohanty D (2010) SBSPKS: structure based sequence analysis of polyketide synthases. Nucleic Acids Res 38:W487-W496

4. Arias P, Fernandez-Moreno MA, Malpartida F (1999) Characterization of the pathway-specific positive transcriptional regulator for actinorhodin biosynthesis in Streptomyces coelicolor A3(2) as a DNA-binding protein. J Bacteriol 181:6958-6968

5. Bachmann BO, Ravel J (2009) Chapter 8. Methods for in silico prediction of microbial polyketide and nonribosomal peptide biosynthetic pathways from DNA sequence data. Methods Enzymol 458:181-217

6. Baltz RH (2008) Renaissance in antibacterial discovery from actinomycetes. Curr Opin Pharmacol 8:557-563

7. Baltz RH (2010) Streptomyces and Saccharopolyspora hosts for heterologous expression of secondary metabolite gene clusters. J Ind Microbiol Biotechnol 37:759-772

8. Bentley SD, Chater KF, Cerdeno-Tarraga AM, Challis GL, Thomson NR, James KD, Harris DE, Quail MA, Kieser H, Harper D, Bateman A, Brown S, Chandra G, Chen CW, Collins M, Cronin A, Fraser A, Goble A, Hidalgo J, Hornsby T, Howarth S, Huang CH, Kieser T, Larke L, Murphy L, Oliver K, O'Neil S, Rabbinowitsch E, Rajandream MA, Rutherford K, Rutter S, Seeger K, Saunders D, Sharp S, Squares R, Squares S, Taylor K, Warren T, Wietzorrek A, Woodward J, Barrell BG, Parkhill J, Hopwood DA (2002) Complete genome sequence of the model actinomycete Streptomyces coelicolor A3(2). Nature 417:141-147

9. Bérdy J (2005) Bioactive microbial metabolites. J Antibiot (Tokyo) 58:1-26

10. Bergmann S, Schumann J, Scherlach K, Lange C, Brakhage AA, Hertweck C (2007) Genomics-driven discovery of PKSNRPS hybrid metabolites from Aspergillus nidulans. Nat Chem Biol 3:213-217

11. Bertrand S, Bohni N, Schnee S, Schumpp O, Gindro K, Wolfender J-L (2014) Metabolite induction via microorganism co-culture: a potential way to enhance chemical diversity for drug discovery. Biotechnol Adv 32:1180-1204

12. Bibb M, Hesketh A (2009) Chapter 4. Analyzing the regulation of antibiotic production in streptomycetes. Methods Enzymol 458:93-116

13. Bibb MJ (2005) Regulation of secondary metabolism in streptomycetes. Curr Opin Microbiol 8:208-215 
14. Bode HB, Bethe B, Höfs R, Zeeck A (2002) Big effects from small changes: possible ways to explore nature's chemical diversity. ChemBioChem 3:619-627

15. Brady SF, Simmons L, Kim JH, Schmidt EW (2009) Metagenomic approaches to natural products from free-living and symbiotic organisms. Nat Prod Rep 26:1488-1503

16. Breton RC, Reynolds WF (2013) Using NMR to identify and characterize natural products. Nat Prod Rep 30:501-524

17. Buevich AV, Williamson RT, Martin GE (2014) NMR structure elucidation of small organic molecules and natural products: choosing ADEQUATE vs HMBC. J Nat Prod 77:1942-1947

18. Camp D, Davis RA, Campitelli M, Ebdon J, Quinn RJ (2012) Drug-like properties: guiding principles for the design of natural product libraries. J Nat Prod 75:72-81

19. Cheatham SF, Kline M, Sasaki RR, Blinov KA, Elyashberg ME, Molodtsov SG (2010) Enhanced automated structure elucidation by inclusion of two-bond specific data. Magn Res Chem 48:571-574

20. Cimermancic P, Medema MH, Claesen J, Kurita K, Wieland Brown LC, Mavrommatis K, Pati A, Godfrey PA, Koehrsen M, Clardy J, Birren BW, Takano E, Sali A, Linington RG, Fischbach MA (2014) Insights into secondary metabolism from a global analysis of prokaryotic biosynthetic gene clusters. Cell $158: 412-421$

21. Colson S, Stephan J, Hertrich T, Saito A, van Wezel GP, Titgemeyer F, Rigali S (2007) Conserved cis-acting elements upstream of genes composing the chitinolytic system of streptomycetes are DasR-responsive elements. J Mol Microbiol Biotechnol 12:60-66

22. Colson S, van Wezel GP, Craig $M$, Noens EE, Nothaft $H$, Mommaas AM, Titgemeyer F, Joris B, Rigali S (2008) The chitobiose-binding protein, DasA, acts as a link between chitin utilization and morphogenesis in Streptomyces coelicolor. Microbiology 154:373-382

23. Cooper MA, Shlaes D (2011) Fix the antibiotics pipeline. Nature 472:32

24. Corre C, Challis GL (2009) New natural product biosynthetic chemistry discovered by genome mining. Nat Prod Rep 26:977-986

25. Cortina NS, Krug D, Plaza A, Revermann O, Müller R (2012) Myxoprincomide: a natural product from Myxococcus xanthus discovered by comprehensive analysis of the secondary metabolome. Angew Chem Int Ed 51:811-816

26. Craig M, Lambert S, Jourdan S, Tenconi E, Colson S, Maciejewska $M$, Ongena $M$, Martin JF, van Wezel $G$, Rigali $S$ (2012) Unsuspected control of siderophore production by $\mathrm{N}$-acetylglucosamine in streptomycetes. Environ Microbiol Rep 4:512-521

27. Cruz-Morales P, Vijgenboom E, Iruegas-Bocardo F, Girard G, Yanez-Guerra LA, Ramos-Aboites HE, Pernodet JL, Anne J, van Wezel GP, Barona-Gomez F (2013) The genome sequence of Streptomyces lividans 66 reveals a novel tRNA-dependent peptide biosynthetic system within a metal-related genomic island. Genome Biol Evol 5:1165-1175

28. de Jong A, van Heel AJ, Kok J, Kuipers OP (2010) BAGEL2: mining for bacteriocins in genomic data. Nucleic Acids Res 38:W647-W651

29. Demain AL (1991) Production of beta-lactam antibiotics and its regulation. Proc Natl Sci Counc Repub China B 15:251-265

30. Doroghazi JR, Albright JC, Goering AW, Ju K-S, Haines RR, Tchalukov KA, Labeda DP, Kelleher NL, Metcalf WW (2014) A roadmap for natural product discovery based on large-scale genomics and metabolomics. Nat Chem Biol 10:963-970

31. Drawz SM, Bonomo RA (2010) Three decades of $\beta$-lactamaselactamase inhibitors. Clin Microbiol Rev 23:160-201
32. Elshahawi SI, Shaaban KA, Kharel MK, Thorson JS (2015) A comprehensive review of glycosylated bacterial natural products. Chem Soc Rev (in press)

33. Exarchou V, Godejohann M, Beek TAV, Gerothanassis IP, Vervoort J (2003) LC-UV-solid-phase extraction-NMR-MS combined with a cryogenic flow probe and its application to the identification of compounds present in Greek oregano. Anal Chem 75:6288-6294

34. Fedorova ND, Moktali V, Medema MH (2012) Bioinformatics approaches and software for detection of secondary metabolic gene clusters. Methods Mol Biol 944:23-45

35. Fisher JF, Meroueh SO, Mobashery S (2005) Bacterial resistance to $\beta$-lactam antibiotics: compelling opportunism, compelling opportunity. Chem Rev 105:395-424

36. Floriano B, Bibb M (1996) afsR is a pleiotropic but conditionally required regulatory gene for antibiotic production in Streptomyces coelicolor A3(2). Mol Microbiol 21:385-396

37. Fu P, Jamison M, La S, Macmillan JB (2014) Inducamides A - C, chlorinated alkaloids from an RNA polymerase mutant strain of Streptomyces sp. Org Lett 16:5656-5659

38. Gaudêncio SP, Pereira F (2015) Dereplication: racing to speed up the natural products discovery process. Nat Prod Rep 32:779-810

39. Genilloud O, Gonzalez I, Salazar O, Martin J, Tormo JR, Vicente F (2011) Current approaches to exploit actinomycetes as a source of novel natural products. J Ind Microbiol Biotechnol 38:375-389

40. Gottelt M, Kol S, Gomez-Escribano JP, Bibb M, Takano E (2010) Deletion of a regulatory gene within the $c p k$ gene cluster reveals novel antibacterial activity in Streptomyces coelicolor A3(2). Microbiology 156:2343-2353

41. Grkovic T, Pouwer RH, Vial ML, Gambini L, Noël A, Hooper JNA, Wood SA, Mellick GD, Quinn RJ (2014) NMR fingerprints of the drug-like natural-product space identify iotrochotazine A: a chemical probe to study Parkinson's disease. Angew Chem Int Ed 53:6070-6074

42. Grkovic T, Pouwer RH, Wang Q, Guymer GP, Holst J, Quinn RJ (2015) LAT transport inhibitors from Pittosporum venulosum identified by NMR fingerprint analysis. J Nat Prod 78:1215-1220

43. Gubbens J, Zhu H, Girard G, Song L, Florea BI, Aston P, Ichinose K, Filippov DV, Choi YH, Overkleeft HS, Challis GL, van Wezel GP (2014) Natural product proteomining, a quantitative proteomics platform, allows rapid discovery of biosynthetic gene clusters for different classes of natural products. Chem Biol 21:707-718

44. Helfrich EJN, Reiter S, Piel J (2014) Recent advances in genome-based polyketide discovery. Curr Opin Biotechnol 29:107-115

45. Herget $S$, Toukach PV, Ranzinger R, Hull WE, Knirel YA, von der Lieth C-W (2008) Statistical analysis of the Bacterial Carbohydrate Structure Data Base (BCSDB): characteristics and diversity of bacterial carbohydrates in comparison with mammalian glycans. BMC Struct Biol 8:35

46. Higo A, Hara H, Horinouchi S, Ohnishi Y (2012) Genomewide distribution of AdpA, a global regulator for secondary metabolism and morphological differentiation in Streptomyces, revealed the extent and complexity of the AdpA regulatory network. DNA Res 19:259-273

47. Hong B, Phornphisutthimas S, Tilley E, Baumberg S, McDowall KJ (2007) Streptomycin production by Streptomyces griseus can be modulated by a mechanism not associated with change in the adpA component of the A-factor cascade. Biotechnol Lett 29:57-64

48. Hosaka T, Ohnishi-Kameyama M, Muramatsu H, Murakami K, Tsurumi Y, Kodani S, Yoshida M, Fujie A, Ochi K (2009) 
Antibacterial discovery in actinomycetes strains with mutations in RNA polymerase or ribosomal protein S12. Nat Biotechnol 27:462-464

49. Hoshino S, Wakimoto T, Onaka H, Abe I (2015) Chojalactones A-C, cytotoxic butanolides isolated from Streptomyces sp. cultivated with mycolic acid containing bacterium. Org Lett 17:1501-1504

50. Hsiao NH, Gottelt M, Takano E (2009) Chapter 6. Regulation of antibiotic production by bacterial hormones. Methods Enzymol 458:143-157

51. Ikeda H, Ishikawa J, Hanamoto A, Shinose M, Kikuchi H, Shiba T, Sakaki Y, Hattori M, Omura S (2003) Complete genome sequence and comparative analysis of the industrial microorganism Streptomyces avermitilis. Nat Biotechnol 21:526-531

52. Johansen KT, Wubshet SG, Nyberg NT, Jaroszewski JW (2011) From retrospective assessment to prospective decisions in natural product isolation: HPLC-SPE-NMR analysis of Carthamus oxyacantha. J Nat Prod 74:2454-2461

53. Kaeberlein T, Lewis K, Epstein SS (2002) Isolating "uncultivable" microorganisms in pure culture in a simulated natural environment. Science 296:1127-1129

54. Kang HS, Brady SF (2014) Arixanthomycins A-C: phylogenyguided discovery of biologically active eDNA-derived pentangular polyphenols. ACS Chem Biol 9:1267-1272

55. Kersten RD, Dorrestein PC (2009) Secondary metabolomics: natural products mass spectrometry goes global. ACS Chem Biol 4:599-601

56. Kersten RD, Yang YL, Xu Y, Cimermancic P, Nam SJ, Fenical W, Fischbach MA, Moore BS, Dorrestein PC (2011) A mass spectrometry-guided genome mining approach for natural product peptidogenomics. Nat Chem Biol 7:794-802

57. Kersten RD, Ziemert N, Gonzalez DJ, Duggan BM, Nizet V, Dorrestein PC, Moore BS (2013) Glycogenomics as a mass spectrometry-guided genome-mining method for microbial glycosylated molecules. Proc Natl Acad Sci U S A 110:4407-4416

58. Kim HK, Choi YH, Verpoorte R (2010) NMR-based metabolomic analysis of plants. Nat Protoc 5:536-549

59. Kim HK, Choi YH, Verpoorte R (2011) NMR-based plant metabolomics: where do we stand, where do we go? Trends Biotechnol 29:267-275

60. Kim SH, Traag BA, Hasan AH, McDowall KJ, Kim BG, van Wezel GP (2015) Transcriptional analysis of the cell divisionrelated ssg genes in Streptomyces coelicolor reveals direct control of $s s g R$ by AtrA. Antonie Van Leeuwenhoek 108:201-213

61. Kövér KE, Hruby VJ, Uhrin D (1997) Sensitivity- and gradient-enhanced heteronuclear coupled/decoupled HSQC-TOCSY experiment for measuring long-range heteronuclear coupling constants. J Magn Res 129:125-129

62. Krug D, Müller R (2014) Secondary metabolomics: the impact of mass spectrometry-based approaches on the discovery and characterization of microbial natural products. Nat Prod Rep 31:768-783

63. Kuehnbaum NL, Britz-Mckibbin P (2013) New advances in separation science for metabolomics: resolving chemical diversity in a post-genomic era. Chem Rev 113:2437-2468

64. Lambert M, Stærk D, Hansen SH, Sairafianpour M, Jaroszewski JW (2005) Rapid extract dereplication using HPLC-SPE-NMR: analysis of isoflavonoids from Smirnowia iranica. J Nat Prod 68:1500-1509

65. Laureti L, Song L, Huang S, Corre C, Leblond P, Challis GL, Aigle B (2011) Identification of a bioactive 51-membered macrolide complex by activation of a silent polyketide synthase in Streptomyces ambofaciens. Proc Natl Acad Sci U S A 108:6258-6263

66. Lautru S, Challis GL (2004) Substrate recognition by nonribosomal peptide synthetase multi-enzymes. Microbiology 150:1629-1636
67. Lee PC, Umeyama T, Horinouchi S (2002) afs $S$ is a target of AfsR, a transcriptional factor with ATPase activity that globally controls secondary metabolism in Streptomyces coelicolor A3(2). Mol Microbiol 43:1413-1430

68. Ling LL, Schneider T, Peoples AJ, Spoering AL, Engels I, Conlon BP, Mueller A, Schaberle TF, Hughes DE, Epstein S, Jones M, Lazarides L, Steadman VA, Cohen DR, Felix CR, Fetterman KA, Millett WP, Nitti AG, Zullo AM, Chen C, Lewis K (2015) A new antibiotic kills pathogens without detectable resistance. Nature 517:455-459

69. Liu G, Chater KF, Chandra G, Niu G, Tan H (2013) Molecular regulation of antibiotic biosynthesis in Streptomyces. Microbiol Mol Biol Rev 77:112-143

70. Liu H, Zheng A, Liu H, Yu H, Wu X, Xiao C, Dai H, Hao F, Zhang L, Wang Y, Tang H (2012) Identification of three novel polyphenolic compounds, origanine $\mathrm{A}-\mathrm{C}$, with unique skeleton from Origanum vulgare L. using the hyphenated LC-DADSPE-NMR/MS methods. J Agric Food Chem 60:129-135

71. Ma J, Cao Q, Mcleod SM, Ferguson K, Gao N, Breeze AL (2015) Target-based whole-cell screening by ${ }^{1} \mathrm{H}$ NMR spectroscopy. Angew Chem Int Ed 54:4764-4767

72. Ma J, McLeod S, MacCormack K, Sriram S, Gao N, Breeze AL, Hu J (2014) Real-time monitoring of New Delhi Metallo$\beta$-Lactamase activity in living bacterial cells by ${ }^{1} \mathrm{H}$ NMR Spectroscopy. Angew Chem Int Ed 53:2130-2133

73. Mahr K, van Wezel GP, Svensson C, Krengel U, Bibb MJ, Titgemeyer F (2000) Glucose kinase of Streptomyces coelicolor A3(2): large-scale purification and biochemical analysis. Antonie Van Leeuwenhoek 78:253-261

74. Mahrous EA, Farag MA (2015) Two dimensional NMR spectroscopic approaches for exploring plant metabolome: a review. J Adv Res 6:3-15

75. Månsson M, Phipps RK, Gram L, Munro MHG, Larsen TO, Nielsen KF (2010) Explorative solid-phase extraction (E-SPE) for accelerated microbial natural product discovery, dereplication, and purification. J Nat Prod 73:1126-1132

76. Mao XM, Luo S, Zhou RC, Wang F, Yu P, Sun N, Chen XX, Tang Y, Li YQ (2015) Transcriptional regulation of the daptomycin gene cluster in Streptomyces roseosporus by an autoregulator, AtrA. J Biol Chem 290:7992-8001

77. Martin GE (2011) Using 1,1- and 1,n-ADEQUATE 2D NMR data in structure elucidation protocols. Annual Rep NMR Spectr. Elsevier, London, pp 215-291

78. Martin GE, Williamson RT, Dormer PG, Bermel W (2012) Inversion of $1 \mathrm{JCC}$ correlations in 1, n-ADEQUATE spectra. Magn Res Chem 50:563-568

79. Martinez A, Kolvek SJ, Hopke J, Yip CL, Osburne MS (2005) Environmental DNA fragment conferring early and increased sporulation and antibiotic production in Streptomyces species. Appl Environ Microbiol 71:1638-1641

80. Mayer M, Thiericke R (1993) A non-enzymatic reaction in the late biosynthesis of the decarestrictine family. J Antibiot (Tokyo) 46:1372-1380

81. Medema M, Blin K, Cimermancic P, de Jager V, Zakrzewski P, Fischbach MA, Weber T, Takano E, Breitling R (2011) antiSMASH: rapid identification, annotation and analysis of secondary metabolite biosynthesis gene clusters in bacterial and fungal genome sequences. Nucleic Acids Res 39:W339-W346

82. Medema MH, Paalvast Y, Nguyen DD, Melnik A, Dorrestein PC, Takano E, Breitling R (2014) Pep2Path: automated mass spectrometry-guided genome mining of peptidic natural products. PLoS Comput Biol 10:e1003822

83. Meyer SW, Köck M (2008) NMR studies of phakellins and isophakellins. J Nat Prod 71:1524-1529

84. Nazari B, Kobayashi M, Saito A, Hassaninasab A, Miyashita K, Fujii T (2012) Chitin-induced gene expression involved 
in secondary metabolic pathways in Streptomyces coelicolor A3(2) grown in soil. Appl Environ Microbiol 79:707-713

85. Newman DJ, Cragg GM (2007) Natural products as sources of new drugs over the last 25 years. J Nat Prod 70:461-477

86. Nguyen DD, Wu CH, Moree WJ, Lamsa A, Medema MH, Zhao X, Gavilan RG, Aparicio M, Atencio L, Jackson C, Ballesteros J, Sanchez J, Watrous JD, Phelan VV, van de Wiel C, Kersten RD, Mehnaz S, De Mot R, Shank EA, Charusanti P, Nagarajan H, Duggan BM, Moore BS, Bandeira N, Palsson BO, Pogliano K, Gutierrez M, Dorrestein PC (2013) MS/MS networking guided analysis of molecule and gene cluster families. Proc Natl Acad Sci U S A 110:E2611-E2620

87. Nicolaou KC, Snyder SA (2005) Chasing molecules that were never there: misassigned natural products and the role of chemical synthesis in modern structure elucidation. Angew Chem Int Ed 44:1012-1044

88. Nothaft H, Rigali S, Boomsma B, Swiatek M, McDowall KJ, van Wezel GP, Titgemeyer F (2010) The permease gene nagE2 is the key to $\mathrm{N}$-acetylglucosamine sensing and utilization in Streptomyces coelicolor and is subject to multi-level control. Mol Microbiol 75:1133-1144

89. Novoa-Carballal R, Fernandez-Megia E, Jimenez C, Riguera R (2011) NMR methods for unravelling the spectra of complex mixtures. Nat Prod Rep 28:78-98

90. Ochi K, Tanaka Y, Tojo S (2014) Activating the expression of bacterial cryptic genes by rpoB mutations in RNA polymerase or by rare earth elements. J Ind Microbiol Biotechnol 41:403-414

91. Ohnishi Y, Ishikawa J, Hara H, Suzuki H, Ikenoya M, Ikeda H, Yamashita A, Hattori M, Horinouchi S (2008) Genome sequence of the streptomycin-producing microorganism Streptomyces griseus IFO 13350. J Bacteriol 190:4050-4060

92. Ongley SE, Bian X, Neilan BA, Müller R (2013) Recent advances in the heterologous expression of microbial natural product biosynthetic pathways. Nat Prod Rep 30:1121-1138

93. Patti GJ, Yanes O, Siuzdak G (2012) Metabolomics: the apogee of the omics trilogy. Nat Rev Mol Cell Biol 13:263-269

94. Pauli GF, Chen SN, Friesen JB, McAlpine JB, Jaki BU (2012) Analysis and purification of bioactive natural products: the AnaPurNa study. J Nat Prod 75:1243-1255

95. Payne DJ, Gwynn MN, Holmes DJ, Pompliano DL (2007) Drugs for bad bugs: confronting the challenges of antibacterial discovery. Nat Rev Drug Discov 6:29-40

96. Perić-Concha N, Long PF (2003) Mining the microbial metabolome: a new frontier for natural product lead discovery. Drug Disc Today 8:1078-1084

97. Rigali S, Nothaft H, Noens EE, Schlicht M, Colson S, Muller M, Joris B, Koerten HK, Hopwood DA, Titgemeyer F, van Wezel GP (2006) The sugar phosphotransferase system of Streptomyces coelicolor is regulated by the GntR-family regulator DasR and links N-acetylglucosamine metabolism to the control of development. Mol Microbiol 61:1237-1251

98. Rigali S, Titgemeyer F, Barends S, Mulder S, Thomae AW, Hopwood DA, van Wezel GP (2008) Feast or famine: the global regulator DasR links nutrient stress to antibiotic production by Streptomyces. EMBO Rep 9:670-675

99. Rottig M, Medema MH, Blin K, Weber T, Rausch C, Kohlbacher O (2011) NRPSpredictor2-a web server for predicting NRPS adenylation domain specificity. Nucleic Acids Res 39:W362-W367

100. Sanchez S, Chavez A, Forero A, Garcia-Huante Y, Romero A, Sanchez M, Rocha D, Sanchez B, Avalos M, Guzman-Trampe S, Rodriguez-Sanoja R, Langley E, Ruiz B (2010) Carbon source regulation of antibiotic production. J Antibiot (Tokyo) 63:442-459

101. Santos-Beneit F, Rodriguez-Garcia A, Sola-Landa A, Martin JF (2009) Cross-talk between two global regulators in
Streptomyces: phoP and AfsR interact in the control of afsS, $p s t S$ and $p h o R P$ transcription. Mol Microbiol 72:53-68

102. Schwab W (2003) Metabolome diversity: too few genes, too many metabolites? Phytochemistry 62:837-849

103. Seger C, Sturm S, Stuppner H (2013) Mass spectrometry and NMR spectroscopy: modern high-end detectors for high resolution separation techniques-state of the art in natural product HPLC-MS, HPLC-NMR, and CE-MS hyphenations. Nat Prod Rep 30:970-987

104. Senior MM, Williamson RT, Martin GE (2013) Using HMBC and ADEQUATE NMR data to define and differentiate longrange coupling pathways: is the Crews rule obsolete? J Nat Prod 76:2088-2093

105. Sidebottom AM, Johnson AR, Karty JA, Trader DJ, Carlson EE (2013) Integrated metabolomics approach facilitates discovery of an unpredicted natural product suite from Streptomyces coelicolor M145. ACS Chem Biol 8:2009-2016

106. Sola-Landa A, Moura RS, Martin JF (2003) The two-component PhoR-PhoP system controls both primary metabolism and secondary metabolite biosynthesis in Streptomyces lividans. Proc Natl Acad Sci U S A 100:6133-6138

107. Southgate R, Elson S (1985) Naturally occurring beta-lactams. Fortschr Chem Org Naturst 47:1-106

108. Sprogøe K, Stærk D, Jäger AK, Adsersen A, Hansen SH, Witt M, Landbo AK, Meyer AS, Jaroszewski JW (2007) Targeted natural product isolation guided by HPLC-SPE-NMR: constituents of Hubertia species. J Nat Prod 70:1472-1477

109. Sugiyama R, Nishimura S, Ozaki T, Asamizu S, Onaka H, Kakeya H (2015) 5-Alkyl-1,2,3,4-tetrahydroquinolines, new membrane-interacting lipophilic metabolites produced by combined culture of Streptomyces nigrescens and Tsukamurella pulmonis. Org Lett 17:1918-1921

110. Swiatek-Polatynska MA, Bucca G, Laing E, Gubbens J, Titgemeyer F, Smith CP, Rigali S, van Wezel GP (2015) Genomewide analysis of in vivo binding of the master regulator DasR in Streptomyces coelicolor identifies novel non-canonical targets. PLoS ONE 10:e0122479

111. Swiatek MA, Gubbens J, Bucca G, Song E, Yang YH, Laing E, Kim BG, Smith CP, van Wezel GP (2013) The ROK family regulator Rok7B7 pleiotropically affects xylose utilization, carbon catabolite repression, and antibiotic production in Streptomyces coelicolor. J Bacteriol 195:1236-1248

112. Swiatek MA, Tenconi E, Rigali S, van Wezel GP (2012) Functional analysis of the $\mathrm{N}$-acetylglucosamine metabolic genes of Streptomyces coelicolor and role in the control of development and antibiotic production. J Bacteriol 194:1136-1144

113. Takano E, Gramajo HC, Strauch E, Andres N, White J, Bibb MJ (1992) Transcriptional regulation of the redD transcriptional activator gene accounts for growth-phase-dependent production of the antibiotic undecylprodigiosin in Streptomyces coelicolor A3(2). Mol Microbiol 6:2797-2804

114. Thaker MN, Wang W, Spanogiannopoulos P, Waglechner N, King AM, Medina R, Wright GD (2013) Identifying producers of antibacterial compounds by screening for antibiotic resistance. Nat Biotechnol 31:922-927

115. Titgemeyer F, Reizer J, Reizer A, Saier MH Jr (1994) Evolutionary relationships between sugar kinases and transcriptional repressors in bacteria. Microbiology 140:2349-2354

116. Tomono A, Tsai Y, Yamazaki H, Ohnishi Y, Horinouchi S (2005) Transcriptional control by A-factor of $s t r R$, the pathwayspecific transcriptional activator for streptomycin biosynthesis in Streptomyces griseus. J Bacteriol 187:5595-5604

117. Tsukioka Y, Yamashita $\mathrm{Y}$, Nakano $\mathrm{Y}$, Oho $\mathrm{T}$, Koga $\mathrm{T}$ (1997) Identification of a fourth gene involved in dTDPrhamnose synthesis in Streptococcus mutans. J Bacteriol 179:4411-4414 
118. Uguru GC, Stephens KE, Stead JA, Towle JE, Baumberg S, McDowall KJ (2005) Transcriptional activation of the pathwayspecific regulator of the actinorhodin biosynthetic genes in Streptomyces coelicolor. Mol Microbiol 58:131-150

119. van Keulen G, Dyson PJ (2014) Production of specialized metabolites by Streptomyces coelicolor A3(2). Adv Appl Microbiol 89:217-266

120. van Wezel GP, McDowall KJ (2011) The regulation of the secondary metabolism of Streptomyces: new links and experimental advances. Nat Prod Rep 28:1311-1333

121. van Wezel GP, McKenzie NL, Nodwell JR (2009) Chapter 5. Applying the genetics of secondary metabolism in model actinomycetes to the discovery of new antibiotics. Methods Enzymol 458:117-141

122. van Wezel GP, White J, Hoogvliet G, Bibb MJ (2000) Application of redD, the transcriptional activator gene of the undecylprodigiosin biosynthetic pathway, as a reporter for transcriptional activity in Streptomyces coelicolor A3(2) and Streptomyces lividans. J Mol Microbiol Biotechnol 2:551-556

123. Vinayavekhin N, Saghatelian A (2009) Regulation of alkyldihydrothiazole- carboxylates (ATCs) by iron and the pyochelin gene cluster in Pseudomonas aeruginosa. ACS Chem Biol 4:617-623

124. Vingadassalon A, Lorieux F, Juguet M, GrL Gof, Gerbaud C, Pernodet J-L, Lautru S (2015) Natural combinatorial biosynthesis involving two clusters for the synthesis of three pyrrolamides in Streptomyces netropsis. ACS Chem Biol 10:601-610

125. Weber T, Charusanti P, Musiol-Kroll EM, Jiang X, Tong Y, Kim HU, Lee SY (2015) Metabolic engineering of antibiotic factories: new tools for antibiotic production in actinomycetes. Trends Biotechnol 33:15-26

126. WHO (2014) Antimicrobial resistance: global report on surveillance. WHO, Geneva

127. Wietzorrek A, Bibb M, Chakraburtty R (1997) A novel family of proteins that regulates antibiotic production in streptomycetes appears to contain an OmpR-like DNA-binding fold. Mol Microbiol 25:1181-1184

128. Willey JM, Gaskell AA (2011) Morphogenetic signaling molecules of the streptomycetes. Chem Rev 111:174-187
129. Wilson MC, Mori T, Ruckert C, Uria AR, Helf MJ, Takada K, Gernert C, Steffens UA, Heycke N, Schmitt S, Rinke C, Helfrich EJ, Brachmann AO, Gurgui C, Wakimoto T, Kracht M, Crusemann M, Hentschel U, Abe I, Matsunaga S, Kalinowski J, Takeyama H, Piel J (2014) An environmental bacterial taxon with a large and distinct metabolic repertoire. Nature 506:58-62

130. Wolfender J-L, Ndjoko K, Hostettmann K (2001) The potential of LC-NMR in phytochemical analysis. Phytochem Anal $12: 2-22$

131. Wu C, Kim HK, van Wezel GP, Choi YH (2015) Metabolomics in the natural products field-a gateway to novel antibiotics. Drug Disc Today Technol (in press)

132. Wu C, van Wezel GP, Choi YH (2015) Identification of novel endophenaside antibiotics produced by Kitasatospora sp. MBT66. J Antibiot (Tokyo) (in press)

133. Wu C, Zacchetti B, Ram AFJ, van Wezel GP, Claessen D, Choi YH (2015) Expanding the chemical space for natural products by Aspergillus-Streptomyces co-cultivation and biotransformation. Sci Rep 5:10868

134. Yang JY, Sanchez LM, Rath CM, Liu X, Boudreau PD, Bruns N, Glukhov E, Wodtke A, De Felicio R, Fenner A, Wong WR, Linington RG, Zhang L, Debonsi HM, Gerwick WH, Dorrestein PC (2013) Molecular networking as a dereplication strategy. J Nat Prod 76:1686-1699

135. Yong D, Toleman MA, Giske CG, Cho HS, Sundman K, Lee K, Walsh TR (2009) Characterization of a new metallo- $\beta$ lactamase gene, bla NDM-1, and a novel erythromycin esterase gene carried on a unique genetic structure in Klebsiella pneumoniae sequence type 14 from India. Antimicrob Agents Chemother 53:5046-5054

136. Zhu H, Sandiford SK, van Wezel GP (2014) Triggers and cues that activate antibiotic production by actinomycetes. J Ind Microbiol Biotechnol 41:371-386

137. Zhu H, Swierstra J, Wu C, Girard G, Choi YH, van Wamel W, Sandiford SK, van Wezel GP (2014) Eliciting antibiotics active against the ESKAPE pathogens in a collection of actinomycetes isolated from mountain soils. Microbiology 160:1714-1725 